P-ISSN $2580-7781$

E-ISSN $2615-3238$

\title{
PENINGKATAN KUALITAS PENDIDIKAN DI INDONESIA UNTUK MENGEJAR KETERTINGGALAN DARI NEGARA LAIN
}

\section{EDUCATION IN INDONESIA AND ABROAD: ADVANTAGES AND LACKS}

\author{
Siti Alifah \\ Prodi Penelitian dan Evaluasi Pendidikan \\ Fakultas Pasca Sarjana Universitas Negeri Jakarta \\ Email: SitiAlifah_9913919007@mhs.unj.ac.id
}

\begin{abstract}
ABSTRAK
Penelitian ini menggambarkan upaya pemerintah untuk mendorong akses dan mutu pendidikan di Indonesia dan dapat mengejar ketertinggalan dari negara lain yang lebih maju, yang kedua untuk mendeskripsikan kelebihan dan kekurangan pendidikan di Indonesia dengan pendidikan di luar negeri.. Penulis menggunakan studi literatur sebagai bentuk penulisan dengan menggunakan sumber atau referensi yang berasal dari arsip, internet, baik berbentuk digital atau berbentuk fisik dan buku. Proses yang sedang berlangsung perlu mendapat dukungan dari semua pihak. Pendidikan di Indonesia mempunyai ciri khas dan kearifan lokal yang tidak dipunyai oleh negara lain. Walaupun dari data PISA kualitas pendidikan di Indonesia masih jauh tertinggal, namun hal ini tidak menyurutkan semua pihak untuk terus meningkatkan kualitas. Tiap sistem mempunyai sisi lemah dan sisi kuat. Hendaknya sistem yang digunakan disesuaikan dengan keadaan masing-masing daerah, sehingga tanpa menghilangkan kearifan lokal yang harus dilestarikan.
\end{abstract}

Kata kunci : Kualitas, Pendidikan, Indonesia.

\begin{abstract}
This study describes the government's efforts to encourage access and quality of education in Indonesia and be able to catch up with other more developed countries, the second is to describe the advantages and disadvantages of education in Indonesia with education abroad. The author uses literature studies as a form of writing using sources or references from archives, the internet, either digital or physical form and books. The ongoing process needs support from all parties. Education in Indonesia has distinctive features and local wisdom that other countries do not have. Although from PISA data the quality of education in Indonesia is still far behind, this does not prevent all parties from continuing to improve quality. Every system has a weak side and a strong side. The system used should be adapted to the circumstances of each region, so that it does not eliminate local wisdom that must be preserved.
\end{abstract}

Keywords: Quality, Education, Indonesia. 
P-ISSN 2580 - 7781

E-ISSN $2615-3238$

\section{PENDAHULUAN}

Pendidikan yang berkualitas pada saat ini masih terus diupayakan oleh pemerintah. Upaya pendidikan yang berkualitas tidak hanya diupayakan oleh pemerintah, pihak lain juga sudah turut andil dalam peningkatan pendidikan. Pihak swasta, lembaga pendidikan serta masyarakat umum. Sebagian masyarakat yang mengerti akan investasi pendidikan, berusaha untuk berlomba-lomba mencari sekolah terbaik untuk putra-putri mereka. Dengan biaya yang mahal dan fasilitas yang mewah, sekolah terbaik itu dapat memberikan pelayanan pendidikan yang baik dan berkualitas. Sebagian masyarakat menyekolahkan anak-anak mereka di dalam negeri namun yang bertaraf Internasional. Biaya sekolah dibayar dengan mata uang dollar, guru-guru yang mengajar di sekolah bertaraf Internasional kewarganegaraan asing.

Kualitas pendidikan menjadi bahan diskusi yang serius dalam decade belakangan ini. Hal ini terjadi karena mutu pendidikan akan sangat menentukan kualitas lulusan hasil pendidikan itu sendiri. Tanpa pendidikan bermutu kecil harapan untuk mendapatkan sumber daya manusia yang bermutu. Oleh sebab itu pendidikan yang bermutu menjadi hal mula yang harus menjadi fokus perhatian semua pihak termasuk masyarakat. Selanjutnya Ishikawa (2006) mendefinisikan kualitas sebagai berikut. (a) quality and customer satisfaction are the same things and (b) quality is a broad concept that goes beyond just product quality to also include the quality of people, processes, and every other aspect of the organization. Artinya kualitas memiliki dua dimensi yaitu: (a) kualitas dan kepuasan pelanggan merupakan hal yang sama, karena bila pelanggan mendapatkan kualitas barang atau jasa, maka akan memperoleh kepuasan. (b) Kualitas merupakan konsep yang luas yang bukan hanya kualitas produk, tetapi juga kualitas orang, proses kerja, dan setiap aspek dari organisasi. Peraturan No 19 tahun 2005 tersebut dinyatakan bahwa, Standar nasional pendidikan memuat kriteria minimal tentang komponen pendidikan yang memungkinkan setiap jenjang dan jalur pendidikan untuk mengembangkan pendidikan secara optimal sesuai dengan karakteristik dan kekhasan programnya. 
P-ISSN 2580 - 7781

E-ISSN 2615 - 3238

Standar nasional pendidikan tinggi diatur seminimal mungkin untuk memberikan keleluasaan kepada masing-masing satuan pendidikan pada jenjang pendidikan tinggi dalam mengembangkan mutu layanan pendidikannya sesuai dengan program studi dan keahlian dalam kerangka otonomi perguruan tinggi. Namun sebagian masyarakat masih beranggapan, bahwa sekolah di luar negeri masih lebih berkualitas dari daripada di dalam negeri. Persepsi seperti itu dapat dipahami, karena masih kurang merata pendidikan berkualitas di Indonesia. Beberapa daerah masih perlu peningkatan kualitas pendidikan pada bidang sumber daya manusia, fasilitas sarana dan prasarana pendidikan. Para orang-tua berusaha memberikan pendidikan yang baik bagi anakanaknya. Berkaitan dengan bidang sumber daya manusia, kehadiran dosen atau guru yang profesional akan mempengaruhi proses belajar mengajar yang baik dan benar. (Sinambela, L. P. : 2017) Hal ini perlu mendapat perhatian, karena pendidikan menjadi hal yang sangat penting bagi anak agar mereka dapat menata masa depannya. Melalui pendidikan yang berkualitas diharapkan keterampilan, pola pikir dan wawasan anak semakin baik. Namun, pendidikan di Indonesia belum semua memiliki fasilitas dan kualitas yang baik dan merata disemua wilayah Indonesia, khuusnya yang berada di pedesaan. Hal ini jauh berbeda dengan sistem pendidikan di Luar Negeri, seperti Malaysia, Singapore dan Australia atau dinegara lain yang lebih maju pendidikannya.

Jika merujuk pada data kualitas pendidikan dapat dilihat dari hasil survei PISA yang merupakan salah satu dasar rujukan untuk menilai kualitas pendidikan di dunia, yang menilai kemampuan membaca, matematika dan sains. Organisasi untuk Kerja Sama Ekonomi dan Pembangunan (OECD) mencatat, peringkat Programme for International Student Assessment (PISA) Indonesia berdasarkan survei tahun 2018 berada dalam urutan bawah. PISA sendiri merupakan metode penilaian internasional yang menjadi indikator untuk mengukur kompetensi siswa Indonesia di tingkat global. Untuk nilai kompetensi Membaca, Indonesia berada dalam peringkat 72 dari 77 negara. Untuk nilai Matematika, berada di peringkat 72 dari 78 negara. Sedangkan 
nilai Sains berada di peringkat 70 dari 78 negara. Nilai tersebut cenderung stagnan dalam 10 - 15 tahun terakhir. Berdasarkan uraian diatas maka penulis ingin menggambarkan upaya pemerintah untuk mendorong akses dan mutu pendidikan di Indonesia dan dapat mengejar ketertinggalan dari negara lain yang lebih maju, yang kedua untuk mendeskripsikan kelebihan dan kekurangan pendidikan di Indonesia dengan pendidikan di luar negeri. Hal ini perlu disajikan dengan tujuan memberikan gambaran umum, bagaimana pendidikan di Indonesia agar dapat ditingkatkan kualitasnya.

\section{METODE PENELITIAN}

Adapun metode penelitian yang digunakan dalam penelitian ini adalah metode kajian pustaka atau studi kepustakaan, metode ini mengkaji sumber yang berisi teori teori yang sesui dengan masalah-masalah penelitian, terutama dari tulisan atau artikel yang dipublikasikan dalam berbagai jurnal ilmiah yang sesuai denga kajian dalam penelitian ini. Kajian pustaka mempunyai manfaat untuk membuat suatu konsep atau teori dasar yang menjadi pijakan studi dalam penelitian. Kajian pustaka atau studi pustaka merupakan kegiatan yang diwajibkan dalam penelitian, khususnya penelitian akademik yang tujuan utamanya adalah menjelaskan aspek teoritis maupun aspek manfaat praktis, sehingga dengan menggunakan metode penelitian ini penulis dapat menyelesaikan masalah sesuai dengan baik dan tepat.

Sebelum melakukan telaah bahan pustaka, peneliti harus mengetahu iterlebih dahulu secara pasti tentang dari sumber mana informasi ilmiah itu akan diperoleh. Adapun beberapa sumber yang digunakan antara lain; buku-buku teks, jurnal ilmiah ,referensi statistik, hasil-hasil penelitian dalam bentuk skripsi, tesis, desertasi, dan internet, serta sumber-sumber lainnya yang relevan (Anwar,S. 2014, Hlm.32).

Selanjutnya penulis menggunakan studi literatur sebagai bentuk penulisan dengan menggunakan sumber atau referensi yang berasal dari arsip, internet, skripsi baik berbentuk digital atau berbentuk fisik dan buku. 
P-ISSN $2580-7781$

E-ISSN $2615-3238$

\section{HASIL DAN PEMBAHASAN PENELITIAN}

A. Upaya Pemerintah untuk mendorong Akses dan Kualitas Pendidikan Indonesia

Tugas pemerintah dalam peningkatan mutu pendidikan di Indonesia adalah bagaimana kualitas pendidikan di Indonesia menjadi merata, tiap daerah mempunyai kualitas sama dengan daerah lain. Tiap daerah di Indonesia mempnyai kekhasan tersendiri yang perlu menjadi tolak ukur keberhasilan pemerataan pendidikan. Kearifan lokal daerah serta karakter menjadi kunci keberhasilan dan kekhasan pendidikan di Indonesia. Indonesia melalui kearifan lokal yang dimiliki oleh setiap daerah diharapkan mampu menjadi primadona dalam mewujudkan pendidikan yang berorientasi global dan berbasis kearifan lokal. Pembelajaran yang terintegrasi dengan muatan lokal memudahkan siswa memahami materi pelajaran melalui lingkungan sekitarnya (Asriati, 2012). Nilai-nilai kearifan lokal dapat dimasukkan dalam berbagai sendi dalam penyelenggaraan pendidikan yang diselenggarakan berdasarkan prinsip-prinsip penyelenggaraan pendidikan (Kusuma, R. S.: 2018) . Untuk meningkatkan kualitas pendidikan di setiap daerah melalui otonomi pendidikan dengan pendekatan yang jelas, terarah, serta berhasil guna, maka diperlukan penerapan prinsip-prinsip manajemen dalam otonomi pendidikan (Suti, M.: 2011). Selanjutnya secara mendasar, hasil pendidikan adalah kualitas sumber daya manusia yang mempunyai kompetensi yang sesuai dengan tujuan pendidikan. Kesesuaian antara hasil yang diharapkan dan hasil yang diperoleh merupakan ukuran mutu pendidikan.

Salah satu indikator dan kunci dari kebehasilan pendidikan adalah input dan proses serta hasil, yang dapat digambarkan dalam skema dibawah ini: 
P-ISSN 2580 - 7781

E-ISSN 2615 - 3238

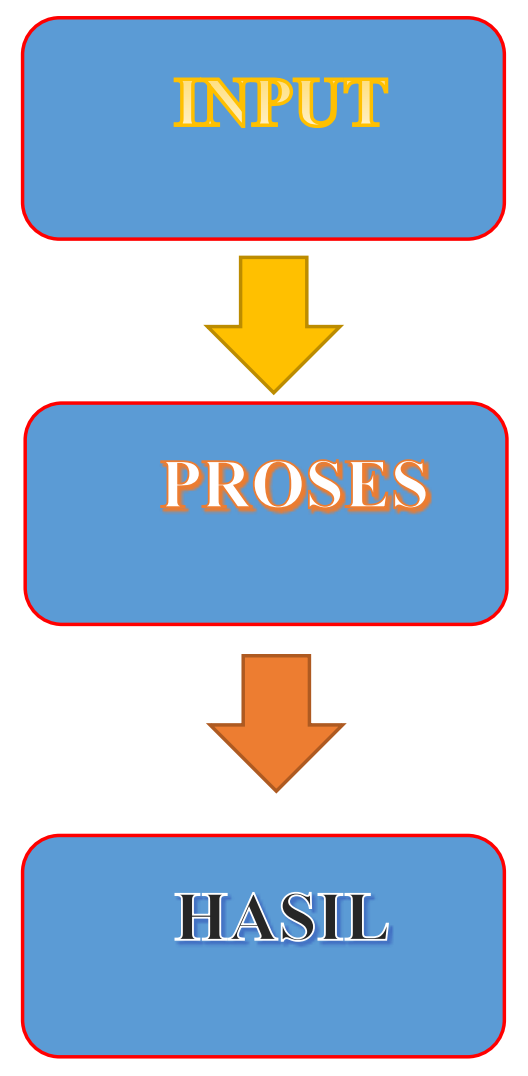

Pemerintah dewasa ini sedang melakukan peningkatan pada aspek input, proses dan hasil. Beberapa program peningkatan pendidikan yang dilakukan adalah memperbaiki proses pendidikan baik berupa pemenuhan sarana dan prasarana mutu, tata kelola, maupun kualitas implementasi kurikulum yang dilakukan oleh satuan pendidikan. Secara sistematik, peningkatan dan pemerataan mutu yang dilakukan pemerintah secara berjenjang dan konsisten. Pada tabel dibawah ini dapat digambarkan peningkatan akses dan mutu pendidikan dengan meluncurkan berbagai bantuan adalah: 
Tabel 1. Tabel jenis bantuan pemerintah

\begin{tabular}{ccc}
\hline No. & Jenis Bantuan & Keterangan \\
\hline 1 & Pembangunan Unit Sekolah Baru & Unit sekolah dibangun \\
& untuk daerah yang belum \\
mepunyai akses sekolah \\
& SMP dan SMA \\
& Pembangunan Ruang kelas baru & Kelas baru ditujukan \\
& untuk menaikkan angka \\
& & partisipasi sekolah \\
& Bantuan Siswa Tidak Mampu melalui & Program ini diberikan \\
& Program Indonesia Pintar & kepada keluarga yang \\
& tidak mampu, sehingga \\
& dapat mengurangi angka \\
& & putus sekolah \\
\end{tabular}

Sumber : Direktorat Pembinaan SMA Kemdikbud ( 2018 )

Kaitan dengan peningkatan mutu ada beberapa ahli pendidikan berpendapat bahwa mutu akan berhubungan langsung dengan 6 komponen dasar sistem pembelajaran dan suprasistemnya (Suparman, A. M : 2012 hlm 38 ), pertama, peserta didik, latar belakang yang baik dan lingkungan keluarga yang mendukung pola belajar anak, akan menentukan keberhasilan belajar siswa, sehingga keterampilan dan pengetahuan awal menjadi modal dalam proses belajar di sekolah, kedua, lulusan yang berkompetensi sesuai harapan, kompetensi siswa kadang tidak sesuai dengan pengguna tenaga kerja atau dalam industry kerja. Hal ini terjadi karena ketidaksesuaian lulusan dengan kemampuan yang dibutuhkan oleh dunia kerja. Dalam penentuan kompetensi ini, ada 3 pihak yang ikut menentukan kompetensi lulusan, yaitu, peserta didik, pengguna lulusan (industri kerja) dan penyelenggara pendidikan. Ketiga adalah proses pembelajaran, proses belajar harus membentuk keingin-tahuan 
P-ISSN 2580 - 7781

E-ISSN $2615-3238$

peserta didik, sehingga belajar menimbulkan gairah keingintahuan peserta didik, selalu ingin berkompetensi menuju keberhasilan, keempat adalah pengajar, suka atau tidak suka pengajar ikut andil dalam peningakatan kualitas pendidikan. Pengajar harus dapat menciptakan proses belajar yang kreatif-inovatif dengan acuan tujuan pembelajaran, keenam adalah kurikulum. Makna kurikulum secara sempit merupakan bahan ajar, atau mata pelajaran atau matakuliah yang berisi materi-materi logis untuk mencapai tujuan pembelajaran. Keenam adalah bahan pembelajaran, penggunaan bahan pembelajaran disesuaikan dengan tujuan pembelajaran. Bahan pembelajaran adalah komponen yang terkait dengan isi setiap mata pelajaran dan harus relevan dengan tujuan pembelajaran, karakteristik peserta didik dan strategi pembelajaran. Menurut hasil penelitian Jumlah sekolah yang terakreditasi yang terbanyak adalah nilai $\mathrm{B}$, dengan tingkat pemenuhan delapan standar nasional untuk SD 73,55\%, SMP 85,97\%, SMA 77,07\% dan SMK 76,15\%. SNP (Standard nasional Pendidikan) yang sulit dicapai adalah standar kompetensi lulusan, ketenagaan, sarana dan prasarana. Variabel standar isi, ketenagaan, sarana dan prasarana, pembiayaan, pengelolaan, penilaian, mempunyai hubungan yang positif yang besarnya bervariasi terhadap variabel standar proses dan komptensi lulusan. Kualitas pelayanan untuk SD telah mencapai 87,4\%, SMP 82,6\% ( Raharjo, S. B : 2012).

B. Kelebihan dan kekurangan pendidikan di Indonesia dengan negara lain.

Sudah menjadi pertimbangan sebagian masyarakat menengah keatas bahwa pendidikan yang berkualitas berhubungan dengan biaya yang mahal, acapkali pendidikan di luar negeri dianggap lebih baik dan unggul karena kualitas. Berikut ini beberapa sumber yang dapat dirangkum beberapa perbedaan sekaligus kekurangan dan kelebihan pendidikan di negara lain. Dalam hal ini penulis tidak bermaksud untuk membanding-bandingkan, namun ingin menjelaskan dari sudut pandang penulis, tanpa bermaksud menyudutkan pendidikan di negara manapun, termasuk Indonesia. 
P-ISSN 2580 - 7781

E-ISSN $2615-3238$

\section{Berkurang Masa Bermain Anak.}

Pada awal belajar taman kanak-kanak, siswa masih dibebani oleh kegiatan belajar yang banyak menyita waktu, hal ini mengurangi waktu bermain anak. Meskipun ada beberapa sekolah TK yang tidak mengharuskan kegiatan belajar yang menyita waktu. Belajar membaca merupakan keharusan bagi siswa TK. Finlandia salah satu negara yang tidak mengharuskan belajar membaca di sekolah taman kanakkanak. Sehingga kemampuan membaca siswa baru dikuasai ketika mereka duduk dibangku sekolah dasar. Siswa TK hanya menggali bakat mereka dengan bermain dibarengi adanya fungsi edukasi. Finlandia menerapkan kegiatan sosial bagi siswa TK. Para siswa tidak dibebani oleh PR (pekerjaan rumah), namun hanya bermain bersama-sama di sekolah. Rasio guru dan siswa sebanyak 1: 7. Hal ini akan memudahkan guru untuk menggali bakat dan minat siswa disekolah.

\section{Pemberlakuan Kelas Unggulan}

Pemisahan kelas unggulan dengan kelas biasa, menimbulkan jarak pemisah antara yang pintar dan tidak pintar. Secara psikologis dapat mempengaruhi peserta didik. Beberapa negara tidak memberlakukan sistiem ini. Namun patut dipahami, pemisahan ini ditujukan untuk mengarahkan siswa pandai menjadi lebih fokus.

\section{Diadakan Masa Orientasi Diawal Masuk Sekolah}

Pemberlakuan masa orientasi, pada masa ke masa sering disalahgunakan oleh segelintir oknum, sehingga dapat menimbulkan korban jiwa. Hal ini perlu adanya pengawasan dari berbagai pihak. Penyelenggara pendidikan yang mempunyai otoritas, harus dengan jeli dan konsisten memberikan penjelasan tujuan masa orientasi ini kepada peserta didik dan orang tua. Tujuan kegiatan ini untuk melatih mental para siswa baru, namun aplikasi yang dilaksanakan bertentangan dengan tujuan pembelajaran itu sendiri, sebagai contoh siswa disuruh menggunakan kaos kaki yang berbeda warna, kegiatan yang sering tidak masuk akal, seperti membawa benda-benda yang aneh dan cenderung membuat waktu terbuang percuma. Meskipun demikian saat ini sudah banyak sekolah yang meniadakan kegiatan tersebut dan 
P-ISSN $2580-7781$

E-ISSN $2615-3238$

menggantinya dengan pengenalan sekolah. Di Amerika, siswa baru hanya diberikan penjelasan, seminar, dan pengenalan sekolah baru, sehingga pengetahuan tentang sekolah dapat diterima dengan baik, tanpa dipermalukan. Lain lagi di negara Jepang, mereka di awal sekolah, Jepang mengenalkan konsep "han" dengan membagi siswa menjadi kelompok kecil yang beranggotakan 4 sampai 5 orang. Kelompok ini nantinya akan melakukan segala aktivitas (makan, duduk, belajar) bersama selama satu bulan penuh. Tujuan dari membagi kelompok ini agar timbul rasa solidaritas diantara mereka.

4. Hasil Evaluasi adalah segalanya.

Pemberlakuan Ujian Nasional beberapa waktu lalu, merupakan hasil penentuan kelulusan. Hal ini menimbulkan persepsi bahwa ujian tersebut merupakan sesuatu yang sangat menentukan. Padahal perlu penilaian aspek lain, seperti moral, karakter atau penilaian langsung dari guru. Meskipun demikian pada saat itu pemerintah juga menyatakan bahwa ujian nasional berguna untuk pemetaan kualitas pendidikan diseluruh daerah Indonesia, di 34 provinsi.

\section{KESIMPULAN}

Peningkatan kualitas pendidikan di Indonesia sudah merupkan keharusan dan keniscayaan. Proses yang sedang berlangsung perlu mendapat dukungan dari semua pihak. Pendidikan di Indonesia mempunyai ciri khas dan kearifan lokal yang tidak dipunyai oleh negara lain. Walaupun dari data PISA kualitas pendidikan di Indonesia masih jauh tertinggal, namun hal ini tidak menyurutkan semua pihak untuk terus meningkatkan kualitas. Tiap sistem mempunyai sisi lemah dan sisi kuat. Hendaknya sistem yang digunakan disesuaikan dengan keadaan masing-masing daerah, sehingga tanpa menghilangkan kearifan lokal yang harus dilestarikan. 
P-ISSN $2580-7781$

E-ISSN 2615 - 3238

\section{DAFTAR PUSTAKA}

Asriati, N. (2012). Mengembangkan Karakter Peserta Didik Berbasis Kearifan Lokal melalui Pembelajaran di Sekolah. Jurnal Pendidikan Sosiologi dan Humaniora, 3(2), 106-119, htp://jurnal.untan.ac.id/index.php/JPSH/article/ viewFile/3663/3670.

Anwar Sanusi, Metodologi Penelitian Bisnis,(Jakarta : Salemba Empat,2016), h.32

Ditjen Pendas dan Menengah,2012, Membangun SMA bermutu di Tapal Batas, Direktorat Pembinaan SMA: Jakarta

Kusuma, R. S. (2018). Peran Sentral Kearifan Lokal Dalam Peningkatan Kualitas Pendidikan. PEDAGOGIK: Jurnal Pendidikan, 5(2), 228-239.

Raharjo, S. B. (2012). Evaluasi trend kualitas pendidikan di indonesia. Jurnal Penelitian dan Evaluasi Pendidikan, 16(2), 511-532.

Suti, M. (2011). Strategi peningkatan mutu di era otonomi pendidikan. Jurnal Medtek, $3(2), 1-6$.

Sinambela, L. P. (2017). Profesionalisme Dosen Dan Kualitas Pendidikan Tinggi. Jurnal Sosial dan Humaniora, 2(4).

Ishikawa, Kaoru. (2005). Pengendalian Mutu Terpadu, PT Remaja Rosdakarya, Bandung. 